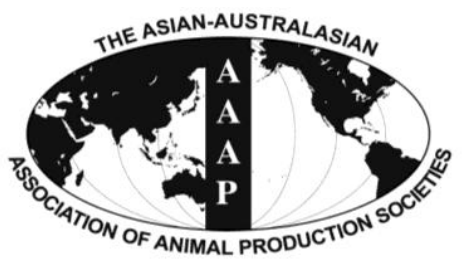

Asian-Aust. J. Anim. Sci.

Vol. 25, No. $10: 1493$ - 1498

October 2012

www.ajas.info

http://dx.doi.org/10.5713/ajas.2012.12152

\title{
Effect of Amaranthus Pigments on Quality Characteristics of Pork Sausages
}

\author{
Cunliu Zhou*, Lin Zhang, Hui Wang and Conggui Chen \\ School of Biotechnology and Food Engineering, Hefei University of Technology, \\ Tunxi No. 193, Hefei, 230009, China
}

\begin{abstract}
The objective of this investigation was to evaluate the possibility of substituting Amaranthus pigments for nitrates in the of manufacture pork sausage. Five treatments of pork sausages ( $5 \%$ fat) with two levels of sodium nitrite $(0$ and $0.015 \%)$, or three levels $(0.1 \%, 0.2 \%$ and $0.3 \%)$ of pigments extracted from red Amaranthus were produced. The addition of Amaranthus pigments resulted in the significant increase of $a^{*}$ values, sensory color, flavor and overall acceptance scores, but the significant reduction of $b^{*}$ values, TBA values and VBN values $(\mathrm{p}<0.05)$. Based mainly on the results of overall acceptance during $29 \mathrm{~d}$ storage, it could be concluded that Amaranthus pigments showed a potential as nitrite alternative for pork sausage manufacture. (Key Words: Amaranthus Pigments, Natural Colorant, Nitrites Alternative, Pork Sausage, Quality Characteristics)
\end{abstract}

\section{INTRODUCTION}

The color is the first impression that consumers have of any meat product. Based on it, consumers make a decision of acceptance or rejection (Mancini and Hunt, 2005). Current methods of meat curing involve usage of nitrite, salt, ascorbate, and phosphates/polyphosphates (Honikel, 2008). Of these food additives, nitrite is the key ingredient and plays a multifunctional role. Especially, it can react with myoglobin to produce the characteristic pink color of cured meats (Zhang et al., 2007). However, it is also found to generate carcinogenic substances such as $\mathrm{N}$ nitrosopyrrolidine and $\mathrm{N}$-nitrosodimethylamine due to its reaction with amines and ammo acids in meat products (Drabik-Markiewicz et al., 2009). Therefore, a series of substances have been attempted to use in meat product as nitrites alternative (Wang et al., 2010). Natural colorants are considered to be safety and healthy and have become increasingly popular with consumers (Østerlie and Lerfall, 2005).

Red Amaranthus (A. tricolor) is rich in natural colorants such as carotenoids, betaxanthins and anthocyanins (Cai et al., 2005). These pigments are water-soluble and thermostable, and thus having been widely used in manufacturing

\footnotetext{
* Corresponding Author: Cunliu Zhou. Tel: +86-55129015058537, Fax: +86-5512901516, E-mail: zhoucl4@hfut.edu.cn Submitted Mar. 20, 2012; Accepted Jun. 2, 2012; Revised Jul. 1, 2012
}

of yogurt, sherbert, ice cream, frozen fruit desserts, candies, frostings, puddings (Freund et al., 1988); and beverages and canned fruit (Huo and Guo, 1994). Pigments extracted from red Amaranthus are also approved for food use in China (Hygienic Standards for Food Additives in China, GB276089) (Jin, 1990). Yet there has been little information published on Amaranthusus pigments used in meat product processing. In this paper, our interests are focused on the effect of natural colorants extracted from red Amaranthusus on color, volatile basic nitrogen (VBN), thiobarbituric acid (TBA) and sensory qualities of pork sausage.

\section{MATERIALS AND METHODS}

\section{Chemicals and materials}

Ethylene diamine tetraacetic acid and ethanol were purchased from Shantou Xilong Chemical Co., Ltd. China. Boric acid, trichloroacetic acid, magnesium oxide, methyl red, methylene blue, TBA and hydrochloric acid were purchased from Shanghai Sinopharm Chemical Reagent Co. Ltd, China.

Fresh red Amaranthus, frozen pork legs, fresh pork backfat, salt and other food additives were purchased from native Carrefour Supermarket.

\section{Extraction of Amaranthus pigments}

Extraction of Amaranthus pigments was similar to the 
procedure described by Cai et al. (1998) with modifications. Samples (300 to $400 \mathrm{~g}$ ) of fresh plant materials (leaves, branches and stem) were obtained from the clean red Amaranthus. The raw materials were cut into approximately small pieces $(0.5 \times 0.5 \mathrm{~cm})$, which were soaked in 4 volumes of water at $25^{\circ} \mathrm{C}$ for $4 \mathrm{~h}$ and filtered with qualitative filter paper. The second extraction was performed with 1 volume of water under the same condition. The combined aqueous extracts were concentrated to $20 \%$ of the original volume under the vacuum condition $(0.1 \mathrm{MPa})$, and centrifuged at $1,280 \mathrm{~g}$ for $10 \mathrm{~min} .1$ volume of $95 \%(\mathrm{~V}: \mathrm{V})$ ethanol was added. The mixture was placed for $2-\mathrm{h}$, and then filtered with qualitative filter paper $(24 \Phi 12.5 \mathrm{~cm})$. The filter was concentrated to $20 \%$ of the original volume under the vacuum condition $(0.1 \mathrm{MPa})$. The dried pigment powder was obtained by a freeze-drying and stored at $4^{\circ} \mathrm{C}$ until further use.

\section{Sausage preparation}

The proper amount of frozen pork legs was thawed for $24 \mathrm{~h}$ at 2 to $4^{\circ} \mathrm{C}$. Lean tissue was trimmed of skin, bone, visible fat and connective tissue. The trimmed lean tissue and fresh pork backfat were mixed with a ratio of 19 to 1 , and then ground with a chopper (SYP-MM12, Guangdong of China). To this meat mixture, $2.5 \%$ salt (based on meat mixture), $0.15 \%$ monosodium glutamate (based on meat mixture), $0.02 \%$ ginger powder (based on meat mixture), $0.02 \%$ pepper powder (based on meat mixture), $5 \%$ water (based on meat mixture), $0.015 \%$ phosphate (based on meat mixture) were added. In addition, the pre-assigned contents of Amaranthus pigments $(0.01 \%, 0.02 \%$ and $0.03 \%$ based on meat mixture, respectively) or sodium nitrite ( 0 and $0.015 \%$ based on meat mixture, respectively) was also added. The meat mixture was mixed thoroughly for another $5 \mathrm{~min}$. The meat mixture was stuffed into polyethylene casing ( $\varnothing: 30 \mathrm{~mm})$ and each sample was $25 \mathrm{~g}$. The raw sausages were stored at $4{ }^{\circ} \mathrm{C}$ for $24 \mathrm{~h}$, and heated to $85 \pm 1^{\circ} \mathrm{C}$ in a water bath for $40 \mathrm{~min}$. Cooled with tap water, the sausages were stored at $4{ }^{\circ} \mathrm{C}$ without packaging for analysis. The samples were analyzed at days 1, 8, 15, 22 and 29. All experiments were performed in triplicates $(n=3)$.

\section{Color measurement}

The color of samples was determined using the Hunter scale with an automatic colorimeter WB-2000 IXA (Beijing Kangguang Instrument Co., Ltd, China). The sausage samples were cut to $3.0 \mathrm{~cm}$ lengths, and then immediately determined. Six measurements for each of three replicates were expressed as $L^{*}$ value, $a^{*}$ value and $b^{*}$ value. The overall lightness or darkness was determined by $\mathrm{L}^{*}$ value $(0$ = black, $100=$ white). Red (positive $=a+$ ) and green (negative $=\mathrm{a}-$ ) intensity are represented on the $\mathrm{a}^{*}$ scale, and yellow (positive $=b+$ ) and blue (negative $=b-$ ) intensity on the $b^{*}$ scale.

TBA

TBA values were performed according to the procedure described by John (2005) with some modifications (in triplicate). Specifically, $5 \mathrm{~g}$ meat samples was taken from the sausage samples, and then mixed with $25 \mathrm{ml}$ solution containing $0.375 \%$ thiobarbituric acid, $15 \%$ trichloro-acetic acid, and $0.25 \mathrm{~mol} / \mathrm{L} \mathrm{HCl}$. The mixture was heated for 10 min in a boiling water bath $\left(100 \pm 1^{\circ} \mathrm{C}\right)$ to develop a pink color, cooled in tap water, and then centrifuged (Model CT14RD, Shanghai Techcomp Ltd., China) at 2,010 $\mathrm{g}$ for $25 \mathrm{~min}$. The absorbance of the supernatant was measured spectrophotometrically (model 722E, Spectrum of Shanghai, China) at $532 \mathrm{~nm}$ against a blank that contained all the reagents minus the meat. The malonaldehyde (MDA) concentration was calculated using an extinction coefficient of $1.56 \times 10^{5} \mathrm{M}^{-1} \mathrm{~cm}^{-1}$ for the pink TBA-MDA pigment (Sinnhuber and Yu, 1958).

The MDA concentration was converted to TBA number (mg MDA/kg meat sample) as follows:

TBA No. $(\mathrm{ppm})=$ Absorbance of the sample $\times 2.77$

\section{VBN}

VBN values were analyzed according to the procedure described in National Standard of China (GB/T5009.442003) with some modifications (in triplicate). To $10 \mathrm{~g}$ meat sample, $100 \mathrm{ml}$ distilled water was added. The sample was homogenized for 2 to $5 \mathrm{~min}$ at $21,000 \mathrm{~g}$, and then placed for $30 \mathrm{~min}$. The homogenate was filtered through a filter paper.

Filtrate $(5 \mathrm{ml})$ was put into a distillation flask. To the filtrate, $5 \mathrm{ml}$ magnesium oxide suspension $(10 \mathrm{~g} / \mathrm{L})$ was added. The mixture was distilled using the micro-Kjeldahl distillation apparatus (Auto K9840 Analyzer, Kjeltec, Beijing Changheng Rongchuang Technology Co., Ltd.). The distillate was collected for $3 \mathrm{~min}$ into $10 \mathrm{ml}$ boric acid $(20 \mathrm{~g} / \mathrm{L})$ containing five-six drops of mixed indicator $(2 \mathrm{~g} / \mathrm{L}$ methyl red indicator alcohol solution and $1 \mathrm{~g} / \mathrm{L}$ methylene blue indicator aqueous solution). The solution was titrated by $0.01 \mathrm{~mol} / \mathrm{L} \mathrm{HCl}$. The $\mathrm{VBN}$ in the sample in terms of milligrams of VBN per $100 \mathrm{~g}$ sausages can be given according to the following formula.

$$
\mathrm{X}=28,000\left(\mathrm{~V}_{1}-\mathrm{V}_{2}\right) \mathrm{c} / \mathrm{m}
$$

Here,

$\mathrm{X}$ : VBN content of the sample $(\mathrm{mg} / \mathrm{l00} \mathrm{g})$,

$\mathrm{V}_{1}$ : the consumption volume of $\mathrm{HCl}$ standard solution for titration of the sample $(\mathrm{ml})$,

$\mathrm{V}_{2}$ : the consumption volume of $\mathrm{HCl}$ standard solution for titration of the blank (ml), 
$\mathrm{C}$ : the actual concentration of $\mathrm{HCl}$ standard solution (mol/L)

$\mathrm{m}$ : the mass of the sample $(\mathrm{g})$.

\section{Sensory evaluation}

Sensory evaluation was performed according to the procedure described by Zhang and others (2010) with some modifications. A sensory panel consisted of 9 food science and Engineering-majored master graduate student (4 males and 5 females). Before conducting the experiment, the panelists were trained in the general sensory descriptive analysis of sausage samples. Before conducting the experiment, the panelists were first trained to evaluate the color, flavor, mouthfeel, slice traits and overall acceptance of the pork sausage according to the method described by Wang and Zhao (2008). Three samples for each treatment were coded with random numbers and liking evaluation for color, flavor, mouthfeel, slice traits and overall acceptance on a 10 -point scale (10 to $8=$ like extremely; 5 to $7=$ neither like nor dislike; 4 to $0=$ dislike extremely). The evaluation was carried out under cool white fluorescent lightning.

\section{Statistics analysis}

Data collected from color measurements, VBN measurements, TBA measurements and sensory evaluation were analyzed by a two-factor (the three levels of Amaranthus pigments and the two levels of sodium nitrite) or a single-factor (storage time for the same treatment) factorial arrangement in a completely randomized design. The data, expressed as mean \pm standard deviation (SD), were analyzed by Excel 2003 (Microsoft official Excel 2003 for Windows). Analysis of variance (ANOVA) was introduced to determine the significance of samples at $p<0.05$ level. When a significant effect was obtained, T-test was used to compare sample means.

\section{RESULTS AND DISCUSSION}

\section{Color}

Figure 1 illustrated the changes in color of pork sausage during storage. As shown in Figure 1, the samples that had more Amaranthus pigments added tended to have lower L* values although the differences of $\mathrm{L}^{*}$ values were not so high to be significant $(p>0.05)$. The similar results were also observed by other groups. Martínez et al. (2006) reported that the addition of red yeast rice, red beet root or betanin could result in the reduction of $\mathrm{L}^{*}$ values of fresh pork sausages. Also, Bloukas et al. (1999) reported that natural colorants such as carminic acid, caramel, betacarotene, paprika-extract and betanin decreased the $\mathrm{L}^{*}$ values of frankfurters. Also, it was found that the addition of Amaranthus pigments affected a* values of the samples

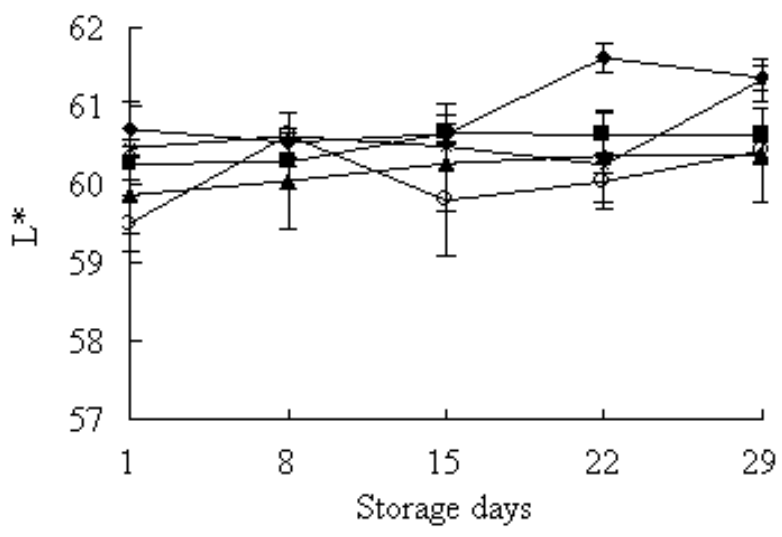

(a)

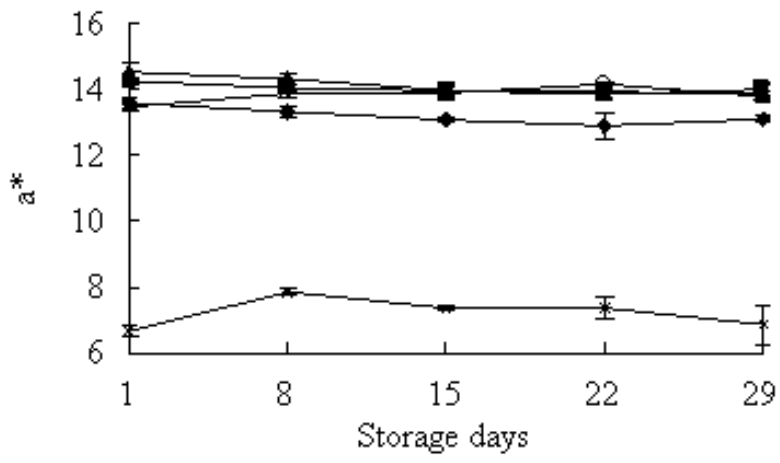

(b)

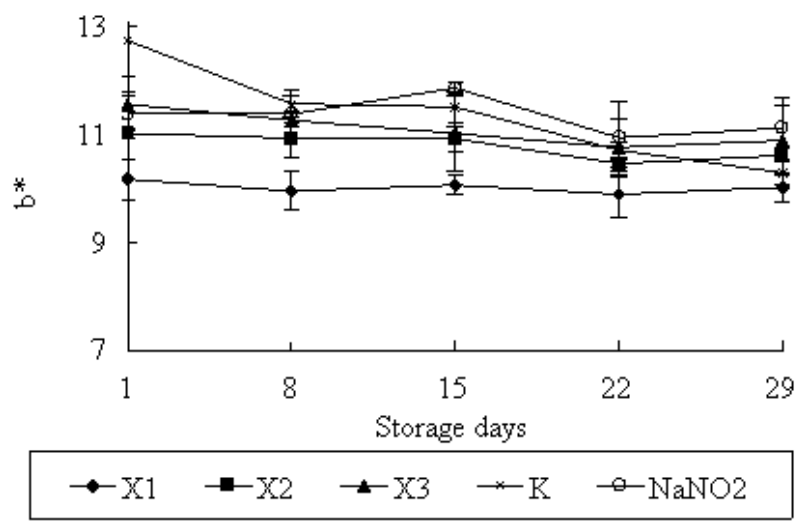

(c)

Figure 1. The changes in color of pork sausages. (a): The changes in $\mathrm{L}^{*}$ of pork sausages; (b): The changes in $\mathrm{a}^{*}$ of pork sausages; (c): The changes in $\mathrm{b}^{*}$ of pork sausages. $\mathrm{X} 1, \mathrm{X} 2$ and $\mathrm{X} 3$ stand for the samples with $0.1 \%, 0.2 \%$ and $0.3 \%$ Amaranthus pigments addition, respectively; $\mathrm{K}$ stands for the controls, $\mathrm{NaNO}_{2}$ stands for the samples with $0.015 \% \mathrm{NaNO}_{2}$ addition.

$(p<0.05)$ and the differences of $a^{*}$ values were so high to be significant $(\mathrm{p}<0.05)$. In comparison to the controls, the addition of low levels ( 0.1 to $0.2 \%$ ) of Amaranthus pigments led to the significant increase of $a^{*}$ values $(\mathrm{p}<0.05)$. Increasing further the level of Amaranthus pigments $(>0.2 \%)$ did not increase $\mathrm{a}^{*}$ values significantly ( $>0.05)$. The samples with Amaranthus pigment addition had equal or even higher $\mathrm{a}^{*}$ values than the $\mathrm{NaNO}_{2}$ samples. 
The changes in $a^{*}$ values of sausage samples were because Amaranthus pigments contain betalains and anthocyanins, which exhibit red or violet (Cai et al., 2005). The addition of Amaranthus pigments had significant influences on $b^{*}$ values of the samples $(p<0.05)$, as shown in Figure 1 . The addition of low levels of Amaranthus pigments (0.1 to $0.2 \%$ ) caused the significant reduction of $b^{*}$ values of the samples $(\mathrm{p}<0.05)$. The results indicated that the Amaranthus pigments samples were darker, more reddish and less yellowish than the control.

Basically, L* values of the $0.1 \%$ Amaranthus pigments samples tended to decrease, while those of the $0.2 / 0.3 \%$ Amaranthus pigments samples had a contrary tendency during storage. Except the $0.1 \%$ Amaranthus pigments samples, $\mathrm{a}^{*}$ and $\mathrm{b}^{*}$ values of the Amaranthus pigments samples decreased during storage. The differences of the $\mathrm{L}^{*}$, $\mathrm{a}^{*}$ and $\mathrm{b}^{*}$ values were not so higher to be significant ( $\mathrm{p}>$ 0.05). The results indicated that color of the Amaranthus pigments samples was relatively stable during storage.

\section{TBA}

Figure 2 showed the changes in TBA values of pork sausage during storage. As expected, TBA values of all the samples increased with storage time $(\mathrm{p}<0.05)$. TBA values are indicators of lipid oxidation. The results revealed that lipid oxidation had occurred during storage. It was also observed that the samples that had Amaranthus pigments added had lower TBA values than the control $(\mathrm{p}<0.05)$, and the samples that had more Amaranthus pigments added tended to have lower TBA values. The results showed that the addition of Amaranthus pigments could prevent lipid against oxidation. Also, antioxidant activity of Amaranthus pigments has reported by Cai et al. (2003). Amaranthus pigments contain carotenoids, betaxanthins, anthocyanins and ther phenolics or polyphenols (Cai et al., 2005), which were important sources of antioxidants (Sokkanha and Tiratanakul, 2006). Therefore, the addition of Amaranthus
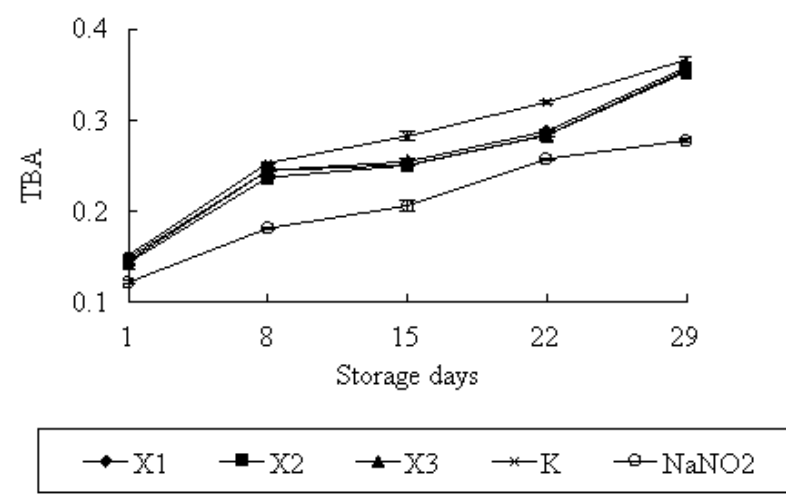

Figure 2. The changes in TBA of pork sausages. TBA: mg malonaldehyde/kg sample. X1, X2 and X3 stand for the samples with $0.1 \%, 0.2 \%$ and $0.3 \%$ Amaranthus pigments addition, respectively; $\mathrm{K}$ stands for the controls; $\mathrm{NaNO}_{2}$ stands for the samples with $0.015 \% \mathrm{NaNO}_{2}$ addition. pigments prevented lipid against oxidation, and thus having lower TBA values during storage.

\section{VBN}

Figure 3 illustrated the changes in volatile basic nitrogen (VBN) of pork sausage samples. VBN values of all the sausage samples significantly $(p<0.05)$ increased as expected when storage time increased. This increase of VBN values of the pork sausages during storage has also been reported by other researchers (Tan et al., 2007). VBN is an index of meat product freshness. Increase amounts of VBN are the result of decomposition of protein during storage by microorganisms. The results showed that decomposition of protein by microorganisms occurred during storage. In addition, it was also observed that the Amaranthus pigments samples had lower VBN values than the control. The differences of VBN values of the Amaranthus pigments samples and the control were not significant $(p>0.05)$ at the first stage of storage, but significant $(\mathrm{p}<0.05)$ at the final stage of storage, indicating that Amaranthus pigments could protect protein from decomposition during storage. Maiyo et al. (2010) reported that leaf extracts of Amaranthus plant species showed a broad spectrum anti-bacterial activity. Therefore, the addition of Amaranthus pigments can prohibit the growth of microorganism, and resulted in the reduction VBN values.

\section{Sensory characteristics}

Sensory characteristics of the samples were also evaluated at $\mathrm{d} 1,8,15,22$ and 29 (Figure 4, data evaluated at $\mathrm{d} 8,15$ and 22 were not shown). Basically, the change in each attribute over time has a decrease tendency at the present work. As shown in Figure 4, the addition of Amaranthus pigments affected strongly sensory color ( $\mathrm{p}<0.05 \%$ ). The samples that had $0.1 \%$ or $0.2 \%$ Amaranthus

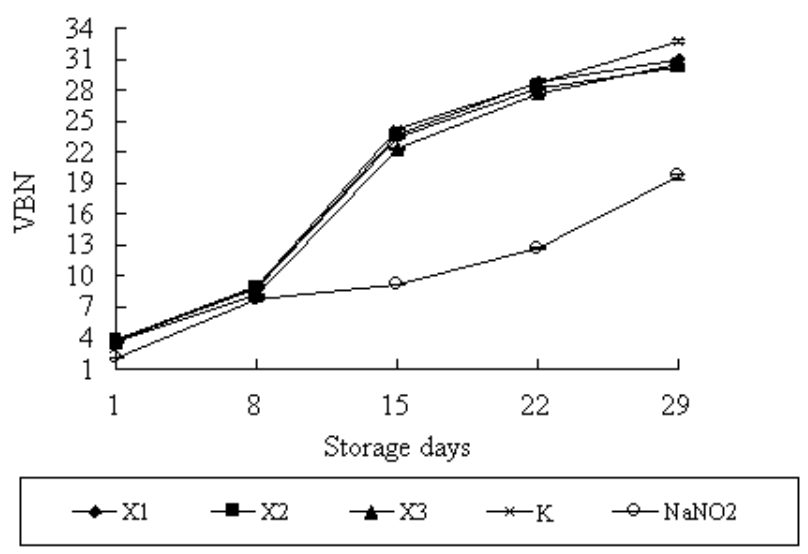

Figure 3. The changes in VBN of pork sausages. VBN: mg malonaldehyde $/ \mathrm{kg}$ sample. X1, X2 and X3 stand for the samples with $0.1 \%, 0.2 \%$ and $0.3 \%$ Amaranthus pigments addition, respectively; $\mathrm{K}$ stands for the controls, $\mathrm{NaNO}_{2}$ stands for the samples with $0.015 \% \mathrm{NaNO}_{2}$ addition. 


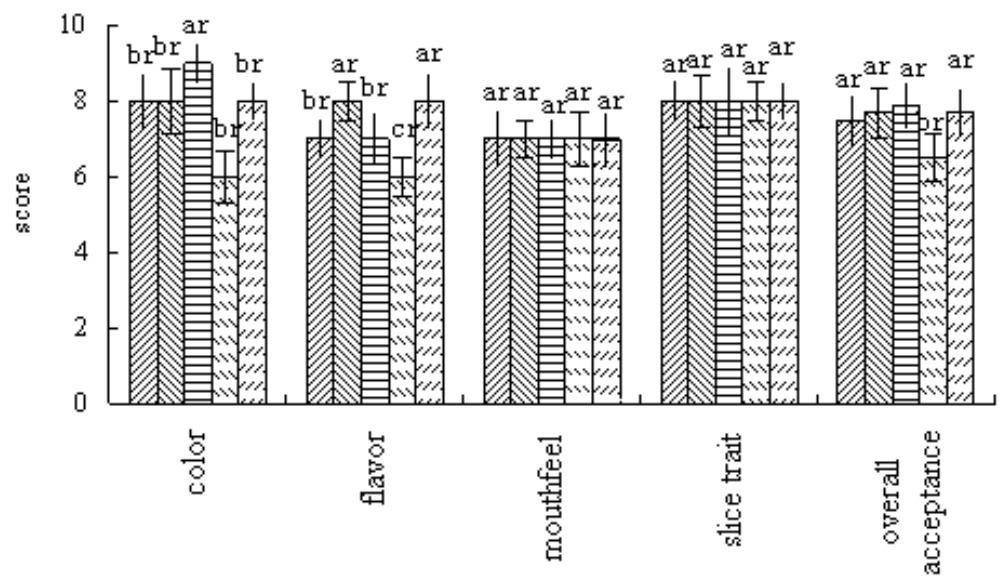

(a)

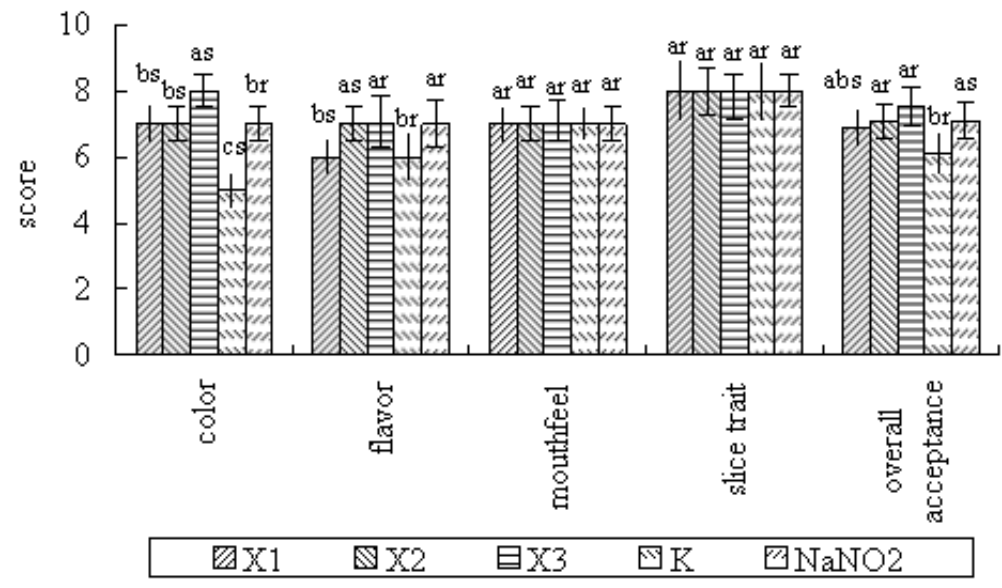

(b)

Figure 4. The changes in sensory qualities of pork sausages during storage. (a) The changes in sensory qualities of pork sausages during 1st d; (b): The changes in sensory qualities of pork sausages during 29th d. X1, X2 and X3 stand for the samples with $0.1 \%, 0.2 \%$ and $0.3 \%$ Amaranthus pigments addition, respectively; $\mathrm{K}$ stands for the controls, $\mathrm{NaNO}_{2}$ stands for the samples with $0.015 \% \mathrm{NaNO}_{2}$ addition. Means \pm SD within the column having unlike letters (a to c) means that the five treatments are significantly different ( $\mathrm{p}<0.05$ ) at the same storage time. Means \pm SD within the row having unlike letters ( $r$ to $s$ ) means that the same treatment are significantly different $(p<0.05)$ at the different storage time.

pigments added had significant higher sensory color scores than the controls $(\mathrm{p}<0.05 \%)$. The samples that had more Amaranthus pigments added tended to have higher sensory color scores $(\mathrm{p}<0.05 \%)$. Amaranthus pigments are redviolet and water soluble phenolic or polyphenol compounds (Cai et al., 1998). The addition of Amaranthus pigments can increase the sample redness, and thus enhancing sensory color scores. It was also observed that Amaranthus pigments affected significantly flavor $(\mathrm{p}<0.05 \%)$. All the Amaranthus pigments samples had higher flavor scores than the controls. Among the Amaranthus pigments samples, the samples with $0.2 \%$ Amaranthus pigments had highest flavor scores, which was equal to the $\mathrm{NaNO}_{2}$ samples. The mechanism of Amaranthus pigments affecting the sample flavor is not fully understood at the present research. But the addition of Amaranthus pigments did not strongly affect mouthfeel and slice traits scores $(p>0.05 \%)$. Mouthfeel and slice traits scores of the samples were between 6.9 and 7.1, between 7.9 and 8.1 during storage, respectively. In view of overall acceptance, the $1.0 \%$ Amaranthus pigments samples had most attractive sensory qualities. Sensory color scores and flavor scores decreased significantly $(\mathrm{p}<0.05 \%)$, but mouthfeel and slice traits scores of the samples did not vary significantly $(p>0.05 \%)$ during storage. In view of overall acceptance, the Amaranthus pigments samples were acceptable during 29-d storage.

\section{CONLUSION}

The pork sausages that had Amaranthus pigments added had more acceptable color than the control. Such samples still had acceptable sensory characteristics and overall 
acceptance during $29 \mathrm{~d}$ storage. In addition, the sausages with more Amaranthus pigments added had lower TBA values and VBN values. Based on the results of overall acceptance, Amaranthus pigments showed a potential in the production of pork sausages to replace nitrites.

\section{ACKNOWLEDGEMENTS}

The authors thank Anhui Science \& Technology Department, National Natural Science Foundation of China and the Ministry of Science and Technology of the People's Republic of China for their financial supports (1208085MC43, 31101240 and 2009GJ30045) of this research, respectively.

\section{REFERENCES}

Bloukas, J. G., I. S. Arvanitoyannis and A. A. Siopi. 1999. Effect of natural colourants and nitrites on colour attributes of frankfurters. Meat Sci. 52:257-265.

Cai Y. Z., M. Sun and H. Corke. 1998. Colorant properties and stability of amaranthus betacyanin pigments. J. Agric. Food Chem. 46:4491-4495.

Cai, Y. Z., M. Sun and H. Corke. 2003. Antioxidant activity of betalains from plants of the Amaranthaceae. J. Agric. Food Chem. 51:2288-2294.

Cai, Y. Z., M. Sun and H. Corke. 2005. Characterization and application of betalain pigments from plants of the Amaranthaceae. Trends Food Sci. Technol. 16:370-376.

Deng, Y., K. Rosenvold, A. H. Karlsson, P. Horn, J. Hedegaard, C. L. Steffensen and H. J. Andersen. 2002. Relationship between thermal denaturation of procine muscle proteins and waterholding capacity. J. Food Sci. 67:1642-1647.

Drabik-Markiewicz, G., K. Van den Maagdenberg, E. De Mey, S. Deprez, T. Kowalska and H. Paelinck. 2009. Role of proline and hydroxyproline in $\mathrm{N}$-nitrosamine formation during heating in cured meat. Meat Sci. 81:479-486.

Freund, P. R., C. J. Washam and M. Maggion. 1988. Natural color for use in foods. Cereal Foods World 33:553-559.

Honikel, K-O. 2008. The use and control of nitrate and nitrite for the processing of meat products. Meat Sci. 78:68-76.

Huo, G. H. and C. Z. Guo. 1994. Exploiting study on the red pigment in Amaranthus tricolor. Acta Agric. Univ. Jiangxiensis 16:106-111 (in Chinese).
Jin, S. J. 1990. Food Additives, 1st Edn. Eastern Chinese Chemistry College Press, Shanghai, China (in Chinese).

John, L., D. P. Cornforth, C. E. Carpenter, O. Sorheim, B. Pettee and D. R. Whittier. 2005. Color and thiobarbituric acid values of cooked top sirloin steaks packaged in modified atmospheres of $80 \%$ oxygen, or $0.4 \%$ carbon monoxide, or vacuum. Meat Sci. 69:441-449.

Maiyo, Z. C., R. M. Ngure, J. C. Matasyoh and R. Chepkorir. 2010. Phytochemical constituents and antimicrobial activity of leaf extracts of three Amaranthus plant species. Afr. J. Biotechnol. 9:3178-3182.

Mancini, R. A. and M. C. Hunt. 2005. Current research in meat color. Meat Sci. 71:100-121.

Martínez, L., I. Cilla, J. A. Beltrán and P. Roncalés. 2006. Comparative effect of red yeast rice (Monascus purpureus), red beet root (Beta vulgaris) and betanin (E-162) on colour and consumer acceptability of fresh pork sausages packaged in a modified atmosphere. J. Sci. Food Agric. 86:500-508.

Østerlie, M. and J. Lerfall. 2005. Lycopene from tomato products added minced meat: Effect on storage quality and colour. Food Res. Int. 38:925-929.

Sinnhuber, R. O. and T. C. Yu. 1958. 2-Thiobarbituric acid method for the measurement of rancidity in fishery products. II. The quantitative determination of malonaldehyde. Food Technol. 12:9-12.

Sokkanha, S. and V. Tiratanakul. 2006. Effect of plastic vinyl cover and shading on the antioxidants level of selected indigenous vegetables. 24 Regional training course in vegetable production, research and extension. Asian Vegetable Research and Development Centre (AVRDC).

Tan, F. J., F. Y. Liao, Y. J. Jhan and D. C. Liu. 2007. Effect of replacing pork backfat with yams (Dioscorea alata) on quality characteristics of Chinese sausage. J. Food Eng. 79:858-863.

Wang, J. X., R. H. Wang, H. B. Wang, M. S. Sun, G. F. Yang, H. Xiao, K. Z. Cai, C. L. Zhou and C. H. Chen. 2010. Research progress in cured cooked-meat pigments derived from blood. Food Sci. 31:449-452. (In Chinese)

Wang, E. X. and J. Zhao. 2008. Application of sensory evaluation in meats. Meat Res. 9:78-82. (In Chinese)

Zhang, F. K., X. Y. Yi, L. X. You, H. Y. Chen and X. J. Liu. 2010. Optimizing fermentation process parameters of fermented beef sausages. Food Sci. 32:182-186. (in Chinese)

Zhang, X., B. H. Kong and Y. L. Xiong. 2007. Production of cured meat color in nitrite-free Harbin red sausage by Lactobacillus fermentum fermentation. Meat Sci. 77:593-598. 